\title{
Sustainability: the dream of international development projects
}

\author{
M. Dulcey Morán \& M. Ferguson \\ Glyndîr University London, UK
}

\begin{abstract}
Human development is now seen as a moral imperative for humanity, wherein developed nations assume a moral responsibility to ensure development of the less developed nations. The basis for this imperative includes socialhumanitarian, political and economic considerations. However, when success is measured in terms of sustainability, then most human development projects have been abject failures. This study sought to examine the factors that impact on sustainability by analysing the experiences of people who deliver human development projects. Nine people who had worked on one or more of five selected information communication technology (ICT) human development projects, participated in the study. The five projects were initiated and managed by ONGAWA, a Spanish NGO, and implemented in South America and Africa. The study adopted the semi-structured interview format. This approach enabled study participants to freely express their lived experiences of planning and delivering human development projects while at the same time ensuring that the pre-defined research question was addressed. The main finding from the study is that in order to foster sustainability a detailed diagnosis should be carried out. Significantly, the diagnosis should use participatory learning and action (PLA) approaches that mandate involving aid-recipients and active stake holders. However, participants' experiences are that donors and funders often desire rapid implementation and visibility. This is often incompatible with the slow, deliberate pace required by PLA approaches. Since NGOs largely rely on donor funding, they often only poorly or rarely use PLA approaches. The study points to the need for non-governmental organisation involved in development aid and human development projects to formulate strategies to educate donors and
\end{abstract}


funders on the necessity and practical implications of PLA if sustainable human development projects are to be fostered.

Keywords: sustainable development, human development project, participatory learning and action, PLA, non-governmental organisation, NGO, Information communication technology, semi-structured interview.

\section{Introduction}

Without sustainability, human development projects can lay no claim on being 'development' processes because development entails irreversible progression from impoverishment to enrichment.

\subsection{Background}

This aligns with the United Nations Development Program (UNDP) Belize [1] definition of human development as:

"the process of enlarging people's choices and improving human capabilities (the range of things that they can do or be in life) and freedoms so they can live a long and healthy life, access to education and a decent standard of living, participate in their community and the decisions that affect their lives".

In the above definition, people's choices may be defined as the range of things that people can do in life. When considering enlarging these choices it is important to be aware of what other choices are available. As a first step, it is worth considering whether the new technologies and modern techniques are better than the previous ones.

However, a significant consideration for human development assistance is the issue of appropriateness, not just for the people who may directly and immediately benefit from the assistance but also for the community where they live. This entails considering three aspects; equity, capability and sustainability.

The answer given by UNDP [2], is that the human development process should be sustainable and equitable and aimed at "expanding human freedoms for people today and for generations to come". When talking about choices, "the sky is not the limit", choices are in fact limited to the rational use of natural resources to an extent that allows marginalised people and future generations to have the same rights to resources. Fig. 1 symbolizes the relation between sustainability and equity. The top-right quadrant represents what development should aim for.

Johansson et al. [3] define a process as "a set of linked activities that take an input and transforms it to create an output" adding that the transformation "should add value to the input and create an output that is more useful and effective to the recipient". For the human development process, the input is composed of people's choices, human capabilities and freedoms and the output is composed of more choices, improved capabilities and freedoms.

The concept of human development is currently imbedded in the Human Development Index, (HDI), which is based on three components; the Gross 
Domestic Product (GPD), literacy rates and life expectancy at birth. The index is a parameter that is calculated relative to the most developed country. However, the HDI is inadequate in 2 respects [4, 5]; Firstly, it excludes soft aspects such as freedom and human rights, a major part of political and social development. Secondly, it is a simple average figure that may not be representative of a population that is not normally distributed.

\begin{tabular}{|c|c|}
\hline $\begin{array}{c}\text { Equitable but } \\
\text { not } \\
\text { sustainable }\end{array}$ & $\begin{array}{c}\text { Human } \\
\text { capabilities } \\
\text { supported } \\
\text { equitably and } \\
\text { sustainably }\end{array}$ \\
\hline $\begin{array}{c}\text { Unsustainable } \\
\text { and } \\
\text { inequitable }\end{array}$ & $\begin{array}{c}\text { Sustainable } \\
\text { but not } \\
\text { equitable }\end{array}$ \\
\hline
\end{tabular}

Figure 1: $\quad$ Sustainable human development [2].

Notwithstanding the above limitations, it is argued that rich countries (those high on the HDI) should have a "moral obligation" [6] to foster the development of poorer countries through grants and donations (foreign aid) [7].

However, writers like Moyo [8] have questioned the concept of foreign aid, by asserting that "aid has been, and continues to be, an unmitigated political, economic and humanitarian disaster for most parts of the developing world".

A major criticism of foreign aid is that it creates dependency. Yunus and Jolis [9] explain that foreign aid may be a soft option, putting both the donor and the recipient at ease while not effecting any human development - the recipient communities and governments develop a dependency mentality while donors feel they are helping by giving aid.

Moyo [8] considers that for Africa, foreign aid should be replaced by foreign investment and sustains her words by observing that:

"over the past thirty years, the most aid-dependent countries have exhibited

an average annual growth rate of minus 0.2 percent" and that "between 1970

and 1998, when aid flows to Africa were at their peak, the poverty rate in

Africa actually rose from 11 per cent to a staggering 66 per cent".

However, Moyo's proposal should be taken with due consideration of mitigating the creation of 'sweat shops', endemic in some Asian countries [10]. Having said this, at a fundamental level, there is now recognition that effective human development should be based on reducing dependency and fostering sustainable independence. 


\subsection{The context of the study}

Since sustainable development requires recipient communities to adopt new approaches, change models such as Hayes' model [11] and Howell's model [12] (depicted in Fig. 2), are possible frameworks for managing development projects.

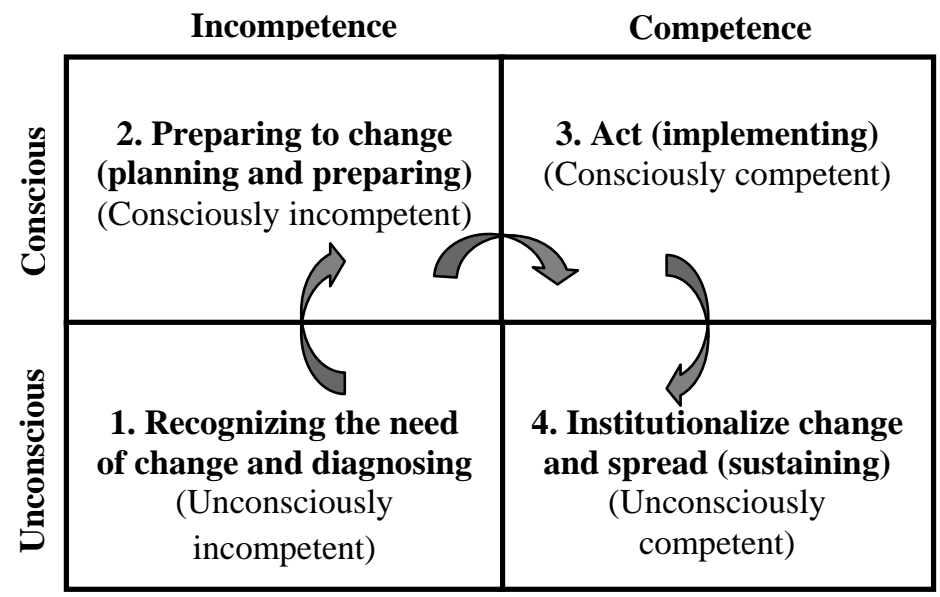

Figure 2: Relationship between the model of human learning, the change management steps as stages of human development projects' cycle of life (adapted from Howell [12]).

The Food and Agricultural Organisation (FAO) [13] states that:

"international, governmental and non-governmental agencies have realised more and more that the main reason of many unsuccessful human development projects was (and still is) the lack of active, effective and lasting participation of the intended beneficiaries”.

It has been reported [14] that human development projects often fail due to a number of reasons, including:

- $\quad$ "Poor planning and programme formulation

- Misallocation of project resources

- Rural people's low sense of power

- $\quad$ Provision of inappropriate technology

- Inadequate promotion

- Ineffective training methodologies

- Lack of enabling policy"

It is conceivable that the above problems could be avoided or minimised by understanding, from the outset, what it is that beneficiary communities actually need, expect and can manage. However, this requires their active involvement, 
not just as passive sources of information but also as protagonists of their own development.

Participatory Learning and Action (PLA) is a family of approaches and methods that enable recipient communities to "share, enhance and analyse their knowledge of life and conditions" [15], by way of answering questions about whether it is worth enlarging their capabilities. PLA facilitates the formulation of recipient-centric development plans, a pre-requisite to sustainable development projects.

\subsection{Aims}

The aim of the study was to determine promoters and inhibitors of PLA.

\section{Methodology}

This was an explanatory qualitative phenomenological study that sought the lived experiences of people working within ONGAWA, a Spanish NGO that delivers ICT human development projects in Latin America and Africa in order to understand their perceptions of inhibitors and facilitators of implementing participatory approaches when planning and delivering human development projects. ONGAWA was chosen because it uses PLA in some stages of its projects' life cycles. The participative philosophy is evident in ONGAWA's stated model of intervention; "supply of basic services, capacity building, political advocacy and strengthening active citizenship" [16].

Primary data for the study derived from semi-structured interviews of a purposive sample of 9 program and project coordinators. The participants were selected because they had or were working on the five active information communications technology (ICT) projects included in the study; although not all of the participants necessarily worked on the same project at the same time. Each interview lasted for about one hour.

The semi-structured questions for the study aligned with the research aim, which was to elicit inhibitors and promoters of participatory processes. Interviews were conducted in Spanish (the first researcher and interviewees' mother tongue). All interviews were recorded and later transcribed and then translated into English by the first researcher to enable triangulation, with the second researcher, during data analysis.

Secondary data for the study came from project reports and information available in the public domain; mainly report archives from the internet.

Bounded segment thematic analysis [17] was chosen for data analysis as it offers access to the original narration.

\section{Findings}

The main factor promoting the implementation of PLA in ONGAWA's projects is ONGAWA's organisational culture. ONGAWA has a transformational leadership style [11] that encourages and facilitates all its workers to implement, 
as far as practicable, the participation of aid-recipients and the study participants came across as committed to this philosophy. There is a sense that they learn from each other's and their own experiences; continuously going through the process of abandoning states of "unconscious incompetence" [12] and learning how to avoid failure and how to make participation work. Some examples of their learning reveal a form of "double loop learning” [11], as they faced errors from the past by exploring possibilities of 'doing things differently' (for example, switching projects from traditional to participatory approaches) or 'doing different things' (for example, by including the "Human Rights approach” [18]).

Participants reported that conditions that are often imposed by donors were their main obstacle to implementing PLA. Significantly, this factor is often out of the control of the NGO; that is if the NGO needs to have access to a broad range of funding and grants.

For example, when discussing the trigger for initiating Project 5 one participant made the following admission:

"We pegged the project application to the priorities of 'Spanish Cooperation', specifically we decided to work with health because that was the priority of our main donor" (Interviewee-9).

\section{A closer examination of 'grant and donor conditions' as the major inhibitor to implementing PLA}

'Grant and donor conditions' was identified as the most significant factor impacting on failure or success in implementing PLA when delivering human development projects and is therefore discussed in more detail in this section.

\subsection{Donors' desire for 'humanitarian visibility'}

Olontuba and Gray [19] analysed the humanitarian aid supply chain, (Fig. 3), and concluded that contrary to conventional business supply chains, NGOs are "more concerned with relationships with donors than with delivery to recipients" because they have to convince donors that they are producing results, a concept that is defined as "humanitarian visibility" [19]. The implications of the desire for "humanitarian visibility" are discussed in sections 4.1.1 to 4.1.3.

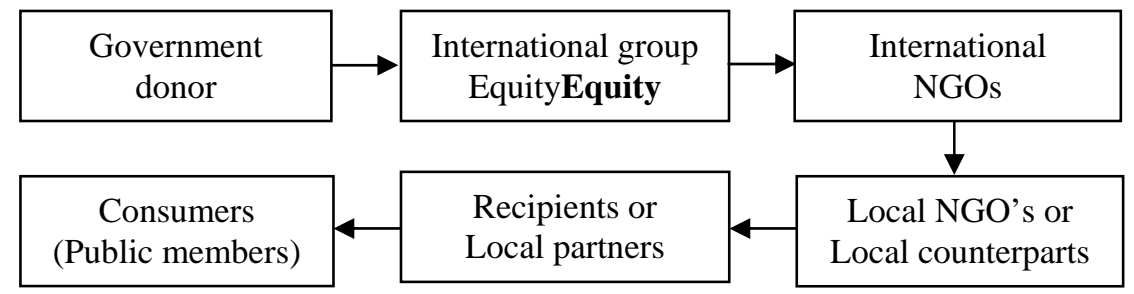

Figure 3: A typical humanitarian supply chain (adapted from Oloruntoba and Gray [19]). 


\subsubsection{Ring-fenced funding or grants}

Funding for development is often ring-fenced to 'humanitarian visibility' activities as observed by one interviewee:

"In many cases, either you have the money in your pocket to identify what you need to do (meaning funding for diagnostics) or you are not in (with a chance to obtain grants)" (Interviewee-9).

This leads NGOs to draft development plans without adequate diagnostics leading to poor specifications of development projects as noted in the following observation:

"Sometimes, projects seem to be a solution for recipients' problems but once you start implementing them, you realise that actually they do not address people's needs. That is because sometimes, things have been planned with the intention of meting conditions to get approval of certain grants" (Interviewee-5).

However it is not only donors but local officials also often prefer NGO's to avoid local bureaucracy by working as implementation units, instead of working directly from inside institutions and helping to build local capacity:

"We used to be continuously pushed by high and medium-ranking officials because they wanted things done quickly without us 'bothering' local people" (Interviewee-7).

The restricted nature of funding is also a major factor for NGOs failing to use PLA as noted in the following statement:

"Generally, there is neither enough economical capacity, nor financial stability to ensure that you can stay working in a place as long as you need to (in order to ensure sustainability)" (Interviewee-9).

This is aggravated by the fact that donors often require NGO's to use grants within set time scales as noted in the following comment:

"In some situations like meetings, I used to feel that recipients did not get the point of what we were saying but despite that we had to carry on because the schedule of projects does not allow you to stop" (Interviewee-7).

\subsubsection{Fostering competition instead of collaboration}

The need to complete projects on time means that NGOs working in the same geographical area do not always coordination their activities [20, 21] and sometimes "poach local qualified staff" [22] from recipient institutions by offering salaries well above local rates, without caring that this weakens the institutions that they should be strengthening. The following comment is a graphic illustration of this:

"That guy (a medium-ranking official) who had come from the capital to enforce the improvement of the Health Information System (HIS), was very enthusiast and got involved with our initiative. Nevertheless, after the first year of the project, when things were moving fast, he left the public institution as he got a job with another NGO" (Interviewee-7) (Project-5).

\subsubsection{Setting objectives unrelated to sustainable development}

A concentrate on "humanitarian visibility" leads NGOs to set easily achievable objectives in order to demonstrate success. This detracts from specifying 
indicators consistent with sustainable human development, as recognized by one of the interviewees, when talking about project 3:

"Our mistake was not to include appropriate objectives' indicators for measuring the quality of results. One example is that although we can say that objectives were achieved, the success in processes of transferring telecommunication networks has not been evident” (Interviewee-2).

This finding is consistent with Birdsall [20] who explains that donors generally do not implement strong systems of evaluation because it could be costly, considering that grants are in the order of billions. The consequences of achieving objectives that do not ensuring sustainability are reflected in following comments regarding different projects:

"I wish we had had some more time in order to make sure that everything we had set out to do materialised and became long-lasting" (Interviewee-4) (Project-1);

"It would have been important to have had a few extra months in order to evaluate how services were performing and how users were evolving" (Interviewee-6) (Project-2);

"We had the intention of continuing working with the ICT Line after delivering the project because we thought it was important to monitor the telecommunications network and give support to maintenance activities by keeping an eye on the performance of the SPM and to ensure that they keep putting in effect the maintenance plan" (Interviewee-8) (Project-5).

\subsection{Serving the home economy}

There is wide agreement [9, 20-23] that a large percentage of the money that is reported as grants or loans, never reaches the recipients because it never leaves the country of origin; paying contracts for the supply of goods and services. Yunus and Jolis [9] a telling illustration of this:

"of the more than 30 USD billion in foreign donor assistance received in the last twenty-six years, 75 per cent never actually reached Bangladesh in the form of cash. Instead, it came as equipment, commodities, supplies, and the cost of consultants, contractors, advisers and experts. Some rich nations use their foreign aid budget to employ their own people and to sell their own goods. The remaining 25 per cent which actually reached Bangladesh in the form of cash went into the hands of a tiny elite of local suppliers, contractors, consultants and experts"

This inhibits recipient-participation because sourcing supplies and services externally does not develop local capabilities. However, participants in this study noted that they have been allowed to source locally as far as practicable. However, problems of capacity impact on their ability to source locally:

"The bidding was stopped twice because there were no candidates meeting all the requirements, including experience in installing telecommunication towers in the jungle” (Interviewee-6) (Project-2);

"It was when we were looking for suppliers of technologies for our projects in order to make them aware of biddings to ensure that we would receive 
enough bids that we realised that local enterprises might not have the capacity to meet the project's reference terms" (Interviewee-7) (Project-5).

There appear to be credible and justifiable reasons for using outside sources. However, sourcing this is not a solution; it is in fact an excuse for not building capacities of local suppliers that are also stakeholders since they belong to the community that is expected to be developed.

\subsection{Promoting a socio-political agenda}

If a project does not recognise the interests of politically powerful local people then it is more likely to fail or be unsustainable, as noted these comments:

"They (high-ranking officials) are able to enumerate the advantages and improvements introduced ...” (Interviewee-8);

"...if you do not have them, the seminar loses its usefulness and sense". (Interviewee-7);

"Our big mistake was not to directly involve the regional government from the beginning of the project. There was no political compromise, and there was no way to oblige them" (Interviewee-4) (Project-1);

"In order to roll-out the re-designed processes, it would have been necessary to modify national directives, something that high-ranking officials were not willing to do". (Interviewee-4) (Project-3).

Thus it is important for donors to make efforts to create political ownership and "to respond to proposal of governments (and non-government groups) rather than themselves proposing and shaping programs" [20]. The following lesson underlines the significance of political ownership:

“Unlike previous projects, where ONGAWA 'hand-picked', who to work with on a project, for this project an invitation was extended to all regional health directors to present a proposal following which the proposal that met criteria related to local leadership and health indicators was selected" (Interviewee5) (Project-1).

From the foregoing discussion, it can be argued that donor's interests are not always altruistic [24, 25] and that the "politics of aid", [23] especially the 'donor's geostrategic interests" [23] often mean that "humanitarian visibility" is valued in preference to sustainable human development. This is consistent with the suggestion that foreign aid is an excuse to veil other interests. It is also argued that donors and agencies of certain countries focus their interventions in regions where 'home' registered MNC have a strong presence or interests [26, 27]. For example, Garzón [26] explains that the Spanish Agency for International Development Cooperation's (AECID) geographical priorities [28] seems to coincide with countries where the most important Spanish MNC (including Telefónica and Repsol YPF) have some kind of interest [29]. That is why some non-profit organisations like Ecologistas en Acción [30] and Cooperación Alternativa y Acción solidaria [31] question AECID for allocating money to MNC's foundation projects, especially those whose Corporate Social Responsibility (CSR) strategy is not evident; an example of which is the project "Strengthening of the economic and social endeavours of the communities in the operation zone of Repsol YPF Ecuador in the Ecuadorian Amazon" executed by 
REPSOL YPF Ecuador Foundation funded by AECID with 150.000€ [32]. Grain [27] cites the global agenda for Genetically Modified (GM) agriculture in proposing that the USAID logo "From the American people" should be switched to "For the American Corporations".

\section{Conclusions}

Grants conditioned by donor preferences or interests limit the scope for PLA and delivering sustainable development. In many cases when donors impose policies that are in conflict with aid-recipient's policies and values, it is unlikely that NGOs like ONGAWA would get high-ranking officials to engage with the project, and even if the project is implemented there might be issues surrounding its sustainability. Furthermore, in many cases donors want to see quick results. This means that it is often unlikely that they will want to put resources in detailed diagnostics, a pre-requisite for sustainable development but one that may take a long time. It is imperative that NGOs and Donors work together through a process of mutual education in order to ensure well-funded sustainable human development projects.

\section{Acknowledgements}

The authors are thankful to Mr Villarroel and staff at ONGAWA, Spain, for facilitating the study and hence the preparation of this paper.

\section{References}

[1] United Nations Development Programme (UNDP) Belize. What is Human Development?, $\quad$ ww.undp.org.bz/human-development/what-is-humandevelopment/

[2] United Nations Development Programme (UNDP), Human Development Report 2011, Sustainability and Equity, a Better Future for All. Palgrave Macmillan: New York, 2011.

[3] Johansson, H., McHugh, P., Pendlebury, A. and Wheeler, W., Business Process Reengineering: Breakpoint Strategies for Market Dominance. John Wiley \& Sons: West Sussex, 1993.

[4] Haq, M., Reflections on Human Development. Oxford University Press, Inc: New Delhi, 1999.

[5] Ranis, G., Stewart, F. and Samman, E., Human Development: Beyond the HDI. Centre Discussion Paper No. 916, produced for the Economic Growth Centre of Yale University. Yale University: New Haven, 2005.

[6] Shleifer, A., Peter Bauer and the Failure of Foreign Aid, Cato Journal, 29(3), pp. 379-90, 2009.

[7] Stern, N., Professor Bauer on Development: A review article, Journal of Development Economics, 1(1), pp. 191-211, 1974. 
[8] Moyo, D., Dead Aid, Why aid is not working and how there is another way for Africa. Penguin Books: London, 2010.

[9] Yunus, M. and Jolis, A., Banker to the poor, the story of the Grameen Bank. Aurum Press Ltd: London, 1999.

[10] Moran, T., Beyond Sweatshops: Foreign Direct Investment and Globalization in Developing Countries, The Bookings Institution: Washington, DC, 2002.

[11] Hayes, J., The Theory and Practice of Change Management, 3rd ed. Palgrave Macmillan: London, 2010.

[12] Howell, W, The empathic communicator. Wadsworth Publishing Co: Belmont, 1982.

[13] Food and Agriculture Organisation of the United Nations (FAO), Participatory Development: Guidelines on Beneficiary Participation in Agricultural and Rural Development, 2nd ed. FAO: Rome, 2003.

[14] Anyaegbunam, C., Mefalopulos, P. and Moetsabi, T., Participatory Rural Communication Appraisal Starting with the people, 2nd ed. SADC Centre of Communication for Development Harare and FAO: Rome, 2004.

[15] Chambers, R., The origins and practice of Participatory Rural Appraisal, World Development, 22(7), pp. 953-69, 1994.

[16] ONGAWA. Who we are, ongawa.org/wp/?page_id=1479.

[17] Riessman, C., Narrative Methods for the Human Sciences. SAGE Publications: London, 2008.

[18] United Nations Population Fund (UNFPA), The Human Rights-Based Approach, www.unfpa.org/rights/approaches.htm

[19] Oloruntoba, R. and Gray, R., Humanitarian aid: an agile supply chain?, Supply Chain Management: An International Journal, 11(2), pp. 115-120, 2006.

[20] Birdsall, N., Seven Deadly Sins: Reflections on Donor Failings. Prepared originally for Conference on Emerging Global Economic Order and Developing Countries (June 28 - July 1 2004). Economic Association: Bangladesh, 2004.

[21] Easterly, W., Are Aid Agencies Improving?, Economic Policy, 22(52), pp. 633-78, 2007.

[22] Knack, S., and Rahman, A., Donor Fragmentation and Bureaucratic Quality in Aid Recipients. World Bank Policy Research Working Paper 3186, World Bank: Washington, DC, 2004.

[23] Woods, N., The Shifting Politics of Foreign Aid, International Affairs (Royal Institute of International Affairs), 81(2), pp. 393-409, 2005.

[24] Boschini, A. and Olofsgard, A., Foreign Aid: an Instrument for Fighting Poverty or Communism?, Paper published by the Social Science Research Network and the World Bank, The World Bank: Washington, DC, 2002.

[25] Griffin, K., Foreign Aid after the Cold War, Development and Change, 22(4), pp. 645-85, 2008.

[26] Garzón, A. La cooperación internacional española (AECID): ¿instrumento para beneficios de los pobres o ganancias de los ricos?, www.rebelion.org/noticia.php?id=142887 
[27] Grain. USAID in Africa: 'For the American Corporations'. www.grain.org/es/article/entries/493-usaid-in-africa-for-the-americancorporations

[28] Spanish Agency for International Development Cooperation (AECID). Where we cooperate- Geographical Priorities, www.aecid.es/en/dondecooperamos/

[29] Chislett, W. Spain's Multinationals: the Dynamic Part of an Ailing Economy (WP). Www.realinstitutoelcano.org/wps/portal/rielcano_eng/ Print?WCM_GLOBAL_CONTEXT=/wps/wcm/connect/elcano/Elcano_in/ Zonas_in/DT17-2011\#C3

[30] Ecologistas en Acción (2012). No a la financiación de la AECID de la Fundación Repsol-YPF, www.ecologistasenaccion.org/article22559.html.

[31] Cooperación Alternativa y Acción solidaria (2012). La Agencia Española de Cooperación financia la anti-cooperación petrolera en Ecuador: Repsol YPF, www.cooperacionalternativa.org/index.php/home/1-general/171-laagencia-espanola-de-cooperacion-financia-la-anticooperacion-petrolera-enecuador-repsol-ypf

[32] Spain, Boletín Oficial del Estado (BOE). III. Otras disposiciones Ministerio de Asuntos Exteriores y de Cooperación. Resolución de 31 de enero de 2012, de la Presidencia de la Agencia Española de Cooperación Internacional para el Desarrollo, por la que se publican las ayudas de convocatoria abierta y permanente correspondientes al año 2011. www.boe.es/boe/dias/2012/05/14/pdfs/BOE-A-2012-6347.pdf 